\title{
IT Project Investment Decision Analysis under Uncertainty
}

\author{
Suling Jia ${ }^{1} \mathrm{Na} \mathrm{Xue}^{1}$ Dongyan $\mathrm{Li}^{1}$ \\ ${ }^{1}$ School of Economics and Management, Beijing University of Aeronautics and Astro- \\ nautics, Beijing 100191, China.Email: jiasul@yeah.net
}

\begin{abstract}
When to implement IT investment is important, the revenue and cost of IT investment are flustering with great uncertainty, so defining rational their variation is the base for assessing the value and occasion of IT investment. The IT investment cost is described by geometrical Brownian motion, and the income is described by geometrical Brownian motion with jump. The theory of real option is applied considering value of wait. With Dynamic Programming, the IT investment decision model is based on that the investment and its income are stochastic. The best investment time and option value are defined by solution of the decision making model and it will help making correct decision of enterprises.
\end{abstract}

Keywords: IT investment evaluation, Real options, Dynamic Programming, Stochastic Process

\section{Introduction}

Since the 1990s, information technology represented by computer has been widely used in business management, design and manufacturing. Information investments of enterprises in financial management, management information systems (MIS), office automation (OA) and other primary applications have shown its superiority. Currently, the focus of information technology investment will shift to the construction of a comprehensive enterprise resource planning (ERP), data warehouse and decision support system (DSS) ${ }^{[1]}$.

The net present value (NPV), internalrate-of-return (IRR) and pay-back period investment appraisal techniques and so on are typical traditional methods dealing with the project investment options. However, IT project investment has characteristics of high uncertainty and high risk. The discounted cash flow method (DCF) as the representative of the traditional project valuation methods should not be a good description of the risk of project cash flow characteristics, they can not reflect the cost and income of IT project investment which has a strong change in the characteristics of random, so that they are easy to underestimate the strategic significance value of the project [2].

In recent years, domestic and foreign scholars studied on the IT investment from different perspectives.

With the consideration that traditional evaluation methods incorporating risk analysis techniques require the input of relative frequencies, Sherif and Alison ${ }^{\text {[3] }}$ proposes a method capable of modeling the effects of both monetary and nonmonetary aspects of an investment option by interval mathematics and possibility theory to handle the uncertainty.

Kleist ${ }^{[4]}$ describes the differences between quality and quantity of information using second order matrix, comes to the conclusion that investment in information technology will improve community output through economics of production pos- 
sibility edge (PPF), and illustrates the best joint between the information technology investment and other investments with no difference curve.

Olafsson ${ }^{[5]}$ discusses the inadequacies of the net present value (NPV) method for evaluating high technology investment projects under uncertainty, introduces management options to decide whether or not to implement the project, takes the uncertainty of the project as a specific value through real options analysis method, and evaluates high technology investment option value with binomial tree as the option pricing model.

Domestic scholars GAO Kun, WU Feng, etc. ${ }^{[6]}$ describes the income variation of ERP projects using the theory of geometric Brownian motion, and creates decision-making model of ERP projects investment based on real options by random integer programming method.

This paper introduces the concept of real options, considering double random changes of the benefit and cost of IT investment under uncertainty. The introduction of real options can obtain the value of delayed investment, and hold back the investment opportunity for better results. Moreover, the paper presents an analysis for the situation of delaying IT investment, showing that it reduces risks and increases the minimum investment critical value as well, thus will help enterprise make right decisions of IT investment.

\section{IT project investment income and cost analysis}

\subsection{Analysis of IT project investment benefit}

Benefit of enterprise from implementing IT project investment is mainly reflected by its business performance. Changes of operating condition caused by market and business content may lead to losing part or even all the original IT system features, so that the benefit from IT system will sharply decline. For that, applying the geometric Brownian motion with jump to describe the changes of IT project investment income, considering the market environment, as well as the impact on IT project investment benefit from changes of business content and process, is more close to reality. The variation of IT investment income can be described by the following stochastic process:

$$
d V=a_{V} V d t+b_{V} V d z_{V}-V d q
$$

In which: ${ }^{a_{V}}$ is the drift coefficient of income, which describes the variation of the IT investment income over time; $b_{V}$ is the fluctuation coefficient of income, which describes the fluctuation of the IT investment income at different times; $d z_{V}$ is an increment of Wiener process, so $d z_{V} \sim N(0,1) ; d q$ is an increment of a Poisson process whose average incidence rate is $\lambda$, which could be represented by (2):

$$
d q= \begin{cases}0 & \text { probability } 1-\lambda d t \\ U & \text { probability } \lambda d t\end{cases}
$$

$\lambda$ represents the average incidence rate of the business jump change, determines the frequency of Poisson jumps; $U$ represents the reduction percentage of the original IT system benefit when enterprise business jump changes.

\subsection{Analysis of IT project investment cost}

Prices of real IT investment in hardware and software products show slight fluctuations affected by supply and demand, and the trend of volatility increases over time. Geometric Brownian motion will be a good description of the variation of IT 
project investment cost, which could be represented by (3):

$$
d I=a_{I} I d t+b_{I} I d z_{I}
$$

In which: ${ }^{a_{I}}$ is the drift coefficient of cost, which describes the variation of the IT investment cost over time; $b_{I}$ is the variance coefficient of cost, which describes the fluctuation of IT investment cost in different times; $d z_{I}$ is an increment of Wiener process; $d q, d z_{V}$ and $d z_{I}$ are independent of each other.

\section{IT project investment decision mak- ing model}

\subsection{Dynamic programming}

According to the Bellman equation, an optimal decision has the following property; regardless of the initial behavior, the remaining decisions compose an optimal decision, which the initial state is the results of the initial behavior:

$$
\Omega_{4}\left(x_{t}, t\right)=\max \left\{\pi_{t}\left(x_{t}, t\right)+\frac{1}{1+\rho} E_{t}\left[\Omega_{\uparrow+1}\left(x_{t+1}, t+\tau\right)\right]\right\}
$$

In which: $\pi_{t}\left(x_{t}, t\right)$ is the immediate profit of the decision at the time of ${ }^{t}$ (i.e. the income from time $t$ to $t+\tau$ ); $\tau$ is the length of time between two decisionmaking point, supposed as unit time; $\rho$ is the discount rate of unit time; $\Omega_{t+1}\left(x_{t+1}, t+\tau\right)$ represents the project value generated by the decision at moment $t+\tau$; the optimal decision at time $t$ will maximize the sum of the immediate benefit and the discount value of future decisions. Extend the above Bellman equation to continuous time, i.e. the length of time of every stage is
$\Delta t, \Delta t \rightarrow 0$; maintain $\pi_{t}\left(x_{t}, t\right)$ as the benefit of unit time, $\rho$ is the discount rate of unit time which is invariable, then in the time period of $\Delta t$, the immediate benefit is $\pi_{t}\left(x_{t}, t\right) \Delta t ; 1 /(1+\rho \Delta t)$ is the discount rate factor, now the Bellman equation becomes:

$$
\Omega(x, t)=\max \left\{\pi(x, t) \Delta t+\frac{1}{1+\rho \Delta t} E\left[\Omega\left(x^{\prime}, t+\Delta t\right)\right]\right\}
$$

For the IT project investment, decisions made at any time can only be an immediate investment or deferring the investment which could not generate cash inflows; and the investment decision is irreversible, once is completed it cannot be revoked. Let $F(x, t)$ express the project value of the investment at time ${ }^{t}$, then the Bellman equation can be written as:

$$
\Omega(x, t)=\max \left\{F(x, t), \frac{1}{1+\rho \Delta t} E\left[\Omega\left(x^{\prime}, t+\Delta t\right)\right]\right\}
$$

Analysis of the above equation shows that, the IT investment will be postponed to a critical state, to make the project value of the immediate investment equal to the value of put off the investment to the next stage; as $\Delta t \rightarrow 0$, then the Bellman equation when IT investment is executed can be written as:

$$
F(x, t)=\frac{1}{1+\rho \Delta t} E\left[F\left(x^{\prime}, t+\Delta t\right)\right]
$$

Multiply both sides by $(1+\rho \Delta t)$, and after an appropriate change, the Bellman equation of the IT investment decisionmaking can be simplified as follows:

$$
\rho F d t=E[d F]
$$




\subsection{Expected benefit under uncer- tainty of both income and cost}

$\lambda$ represents the average incidence rate of the jump changes of business, which determines the frequency of Poisson jumps. If let $T$ represent the time of continuous fluctuation before $V$ jumps down, i.e. enterprise business changes once every $T$ year on average, then the expected value of $T$ can be calculated by the following equation:

$$
E[T]=\int_{0}^{\infty} \lambda T e^{-\lambda T} d T=\frac{1}{\lambda}
$$

Assuming that the current income $V(0)=V_{0}$, and the project life cycle is $n$, if the income of IT investment obeys the geometric Brownian motion with jump represented by formula (1), the discount value of IT investment income can be calculated by $(10)(\rho$ is the discount rate):

$$
V=E\left[\int_{0}^{n} V(t) e^{-\rho t} d t\right]=\int_{0}^{n} V_{0} e^{-\left(\rho-\alpha_{V}-\lambda U\right) t} d t
$$

\subsection{Decision-making model}

If let $F(V, I)$ represent the value of investment opportunity, i.e. the option value of investment, then $F(V, I)=V-I$. Since it will not generate benefit in general before the completion of IT projects, and the return on deferring investment is the expected increasing value of the capital, the Bellman equation of the optimal decision of IT investment can be: $\rho F d t=E(d F)$. In which, the changes of $V$ and $I$ obey the stochastic movements of formula (1) and (3) respectively. Expand $d F$ with Ito's Lemma ${ }^{[7]}$, we have the following formula:

$$
\begin{aligned}
& d F=F_{V}\left(\alpha_{V} V d t+\sigma_{V} V d z_{V}-V d q\right)+F_{I}\left(\alpha_{I} \mathrm{I} d t+\sigma_{I} \mathrm{I} d z_{I}\right) \\
& +\frac{1}{2} F_{V V}\left(\alpha_{V} V d t+\sigma_{V} V d z_{V}-V d q\right)^{2}+\frac{1}{2} F_{I I}\left(\alpha_{I} \mathrm{I} d t+\sigma_{I} \mathrm{I} d z_{I}\right)^{2} \\
& +F_{V I}\left(\alpha_{V} V d t+\sigma_{V} V d z_{V}-V d q\right)\left(\alpha_{I} \mathrm{I} d t+\sigma_{I} \mathrm{I} d z_{I}\right)
\end{aligned}
$$

In which:

$$
\begin{aligned}
& F_{V}=\frac{\partial F(V, I)}{\partial V}, F_{V V}=\frac{\partial^{2} F(V, I)}{\partial V^{2}}, \\
& F_{I}=\frac{\partial F(V, I)}{\partial I}, \quad F_{I I}=\frac{\partial^{2} F(V, I)}{\partial I^{2}}, \\
& F_{V I}=\frac{\partial^{2} F(V, I)}{\partial V \partial I} .
\end{aligned}
$$

Calculate the expectation of $d F$, notice that $d z_{V}$ and $d z_{I}$ are Wiener processes, and let $E\left[d z_{V} d z_{I}\right]=\eta d t$ ( $\eta$ is the correlation coefficient between $d z_{V}$ and $d z_{I}$, representing the degree of relevance between the cost and income of IT investment), we have the following formula:

$$
\begin{aligned}
E(d F)= & \alpha_{V} V F_{V} d t+\frac{1}{2} \sigma_{V}^{2} V^{2} F_{V V} d t+\alpha_{I} I F_{I} d t \\
& +\frac{1}{2} \sigma_{I}^{2} I^{2} F_{I I} d t+\eta \sigma_{V} \sigma_{I} V I F_{V I} d t \\
& -\lambda\{F(V, I)-F[(1-\phi) V, I]\} d t
\end{aligned}
$$

Substitute the formula (12) into Bellman equation $\rho F d t=E(d F)$, we have the following formula:

$$
\begin{aligned}
& \alpha_{V} V F_{V}+\frac{1}{2} \sigma_{V}^{2} V^{2} F_{V V}+\alpha_{I} I F_{I}+\frac{1}{2} \sigma_{I}^{2} I^{2} F_{I I}+\eta \sigma_{V} \sigma_{I} V I F_{V I} \\
& -(\lambda+\rho) F(V, I)+\lambda F[(1-\phi) V, I]=0
\end{aligned}
$$

In addition, $F(V, I)$ must satisfy the following boundary conditions: 


$$
\left\{\begin{array}{l}
F\left(V^{*}, I^{*}\right)=V^{*}-I^{*} \\
\lim _{V \rightarrow 0} F(V, I)=0 \\
F_{V}\left(V^{*}, I^{*}\right)=1 \\
F_{I}\left(V^{*}, I^{*}\right)=-1
\end{array}\right.
$$

In which: $F(V, I)$ represents the critical value of IT project investment option when making optimal decision, $V^{*}$ and $I^{*}$ represents the critical value of IT project investment benefit and cost respectively when making optimal decision.

As the benefit and cost of IT investment are uncertain, given that the best investment timing is determined by the relation between the income and cost of IT investment, in order to simplify the calculation, let $\gamma=V / I, F(V, I)=I f(\gamma)$, and substitute them into (13), (14) to have the following formula:

$$
\begin{aligned}
& \frac{1}{2}\left(\sigma_{V}^{2}-2 \eta \sigma_{V} \sigma_{I}+\sigma_{I}^{2}\right) \gamma^{2} f^{\prime \prime}(\gamma)+\left(\alpha_{V}-\alpha_{I}\right) \gamma f^{\prime}(\gamma) \\
& +\left(\alpha_{I}-\lambda-\rho\right) f(\gamma)+\lambda f[(1-U) \gamma]=0
\end{aligned}
$$

Then the corresponding boundary conditions become into (16):

$$
\left\{\begin{array}{l}
f\left(\gamma^{*}\right)=\gamma^{*}-1 \\
\lim _{\gamma \rightarrow 0} f(\gamma)=0 \\
f^{\prime}\left(\gamma^{*}\right)=1 \\
f\left(\gamma^{*}\right)-\gamma f^{\prime}\left(\gamma^{*}\right)=-1
\end{array}\right.
$$

Let $f(\gamma)=A \gamma^{\beta}$, and substitute it into (16), we will have the following formula:

$$
\gamma^{*}=\frac{V^{*}}{I^{*}}=\frac{\beta}{\beta-1}
$$

$$
A=\frac{(\beta-1)^{\beta-1}}{\beta^{\beta}}
$$

$\beta$ satisfies the following equation (19), and $\beta$ has no analytical solution through analyzing the formula (19). However, the approximate solution can be obtained by numerical calculation:

$$
\begin{aligned}
& \left(\sigma_{V}^{2}-2 \eta \sigma_{V} \sigma_{I}+\sigma_{I}^{2}\right) \beta^{2} \\
& +\left(2 \alpha_{V}-2 \alpha_{I}-{\sigma_{V}}^{2}+2 \eta \sigma_{V} \sigma_{I}-\sigma_{I}^{2}\right) \beta \\
& +2\left(\alpha_{I}-\lambda-\rho\right)+2 \lambda(1-U)^{\beta}=0
\end{aligned}
$$

Through deduction and calculation of the above, it can be concluded that if the changes of income and cost of IT investment obey the stochastic movement represented by formula (1) and (3) respectively, then the critical value of the best IT project investment timing(that is, the demanded minimum investment return rate) $V^{*} / I^{*}$ satisfies formula (17). And the option value of project $F(V, I)$ is determined by the following formula:

$$
F(V, I)= \begin{cases}V-I, & \frac{V}{I}>\frac{V^{*}}{I^{*}} \\ A I \gamma^{\beta}, & \frac{V}{I}<\frac{V^{*}}{I^{*}}\end{cases}
$$

\section{The comparative analysis of the same IT system implemented in dif- ferent enterprises}

If the same IT system (such as ERP, SAP) is implemented in different enterprises in turn, then the latter enterprise can reduce the investment risk by exploring the former situation of implementing the system, but critical value of investment will increase correspondingly as well. The reduction of investment risk shown in formula (2) is the changes of $\lambda$ and $U$. The 
following figure shows the comparative analysis of how different values of $U$ affect the optimal investment critical value using Matlab:

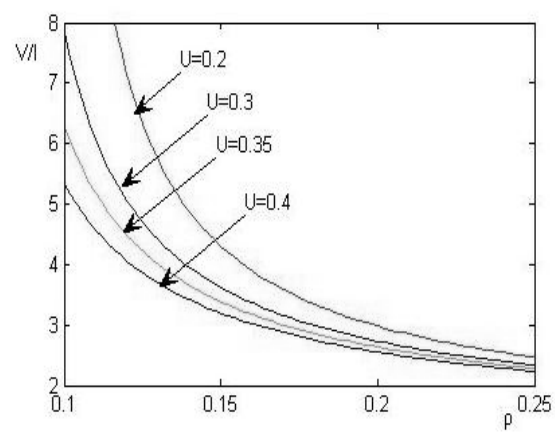

Fig. 1: The curve of the optimal investment critical value with different values of $U$.

As is shown in Figure 1, with the decrease of jump magnitude $U$, the investment critical value $V / I$ increases gradually. That is, although the risk reduces, the minimum critical investment value is correspondingly increasing, which is in line with expectations.

Delaying investment of IT systems increases the optimal investment critical value on one hand, and also reduces the risk and increases the benefit $V$ on the other hand. The following figure represents the change trend of IT project investment benefit with the decreasing of the jump magnitude (other parameters are the same as above).

Seen from the above figure, the investment benefit gradually increases with the decrease of $U$.

The effect of changes of probability $\lambda$ on investment benefit is similar to $U$, and we will not discuss it here.

\section{Case study}

An enterprise intends to investment 1 million to construct IT system for infor- mation construction, and the life cycle of the project is 15 years. The cost of IT project investment obeys the geometric Brownian motion, and in which to calculate the cost drift rate is $a_{I}=0.02$ and the volatility rate is $b_{I}=0.4$ by statistical methods, according to the former information investment market and history data. That is:

$$
d I=0.02 I d t+0.4 I d z
$$

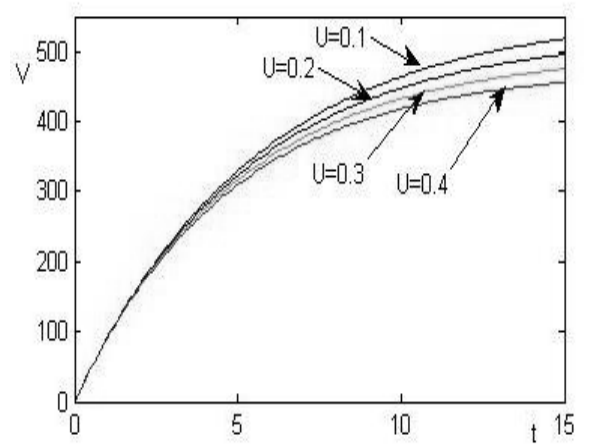

Fig. 2: The curve of the investment benefit with different values of $U$.

The income of IT investment obeys the geometric Brownian motion with jump represented as the formula (1). In which, the sustainable growth rate is $a_{V}=0.03$, the average incidence rate of the jump changes in business is $\lambda=0.2$, the volatility rate is $b_{V}=0.2$, the decline range of IT investment income is $U=0.3$, the subjective discount rates is $\rho=0.2$. The IT investment is completed and the current income is 0.4 million. The correlation coefficient between $d z_{V}$ and $d z_{I}$ is $\eta=0.5$. Then:

$$
d V=0.03 V d t+0.2 V d z_{V}-V d q
$$

In which, 


$$
d q= \begin{cases}0 & \text { probability } 1-0.2 d t \\ 0.3 & \text { probability } 0.2 d t\end{cases}
$$

According to the above parameters, we can obtain that $\beta=2.6957$ by equation (13), and the critical investment value of decision-making is $V^{*} / I^{*}=1.59$. The discounted value of its expected income is $V=168.4$ through formula (6), and the investment cost is 1 million. For that $168.4 / 100=1.68$, which is more than the investment critical value, the IT investment should be implemented. The option value of IT project investment is $F=68.4$.

If the follow-up enterprise invests on the same IT system, the investment risk will reduce because of the experience of the former enterprise. Assuming that the decline range of IT investment benefit of the follow-up enterprise, $U$ drops to 0.1 , then the critical investment value of decision-making becomes $V^{*} / I^{*}=1.71$. The follow-up enterprise should delay the investment for the reason that the investment revenue is lower than the minimum investment revenue.

\section{Conclusion}

This paper introduced the idea of real options, considering double stochastic changes of the benefits and costs of IT investment under uncertainty. It is more flexible and close to reality compared with the tradition discounted cash flow method. The introduction of real options can obtain the value of delayed investment, and hold back the investing opportunity for better results, as a result of avoiding haphazard investment. Mean- while this article presents an analysis of the situation when the enterprise delays IT investment, showing that it increases benefit and raises the minimum investment critical value as well, thus will help enterprise make the right investment decisions.

\section{References}

[1] CCW Research, "2003-2004 Investigations of the Informatization of Six Industries (I)", 03/29/2004 [R], Beijing: CCW Research 2004.

[2] Hodder, James E., and Riggs Henry E, "Pitfalls in Evaluating Risky Project", Harvard Business Review, pp. 128135, 1985.

[3] Sherif Mohamed, Alison K. McCowan, "Modelling project investment decisions under uncertainty using possibility theory", International Journal of Project Management, pp. 231-241, 2001.

[4] Kleist V F, "An approach to evaluating e-business information systems projects", Information Systems Frontiers, pp.249-263, 2003.

[5] Olafsson S, "Making decisions under uncertainty-implications for high technology investments", BT Technology Journal, pp.170-183, 2003.

[6] GAO Kun, WU Feng, and LI Huai-zu, "The uncertainty investment analysis of ERP based on real options", System Engineering Theory and Practice, pp.17-26, 2007.

[7] CHEN mu-fa, MAO yong-hua, "Stochastic Processes Introduction", Beijing: HIGHER EDUCATION PRESS, pp.143-145, 2007. 